\title{
Upaya pencegahan Diabetes Melitus melalui edukasi kesehatan pada masyarakat Kampung Pelita Medika Buluh Cina
}

\author{
Miftah Azrin*, \& Suyanto \\ Universitas Riau \\ *garudaunri@gmail.com
}

\begin{abstract}
Abstrak. Kejadian Diabetes Melitus (DM) tipe 2 di daerah pedesaan menunjukan angka yang terus meningkat. Untuk itu upaya untuk mengendalikan penyakit Diabetes perlu dilakukan melalui edukasi kepada masyarakat. Kami melakukan pengabdian di desa Buluh Cina yang merupakan salah satu desa binaan Kampung Pelita Medika FK UNRI. Edukasi diberikan bersama mahasiswa Kukerta melalui sosialisasi pola makan yang sehat dan pemeriksaan gula darah sebagai faktor risiko. Melalui pengabdian ini diharapkan masyarakat memiliki kesadaran untuk mengendalikan faktor risiko DM di desa Buluh Cina.
\end{abstract}

Kata kunci: DM, Buluh Cina, edukasi kesehatan, pencegahan penyakit

Abstract. The incidence of Type 2 Diabetes Mellitus (DM) in rural areas shows an increasing number. For this reason,
efforts to control diabetes need to be done through education to the public. Community service was conducted in the
village of BuluhCina which is one of the fostered villages of Kampung Pelita Medika FK UNRI. Education is provided
with Kukerta students through socialization of a healthy diet and checking blood sugar as a risk factor. Through this
service, it is hoped that the community will have the awareness to control the risk factors for DM in BuluhCina village.

Keywords: DM, Buluh Cina, health education, disease control

To cite this article: Azrin, M., \& Suyanto. 2020. Upaya Pencegahan Diabetes Melitus Melalui Edukasi Kesehatan Pada Masyarakat Kampung Pelita Medika Buluh Cina. Unri Conference Series: Community Engagement 2: 298302. https://doi.org/10.31258/unricsce.2.298-302

\section{(C) 2020 Authors}

Peer-review under responsibility of the organizing committee of Seminar Nasional Pemberdayaan Masyarakat 2020 


\section{PENDAHULUAN}

Prevalensi diabetes melitus tipe 2 di Provinsi Riau sebesar 1,9\%, angka tersebut sedikit dibawah rata-rata nasional sebesar 2\% berdasarkan hasil riset dari Riset Kesehatan Dasar tahun 2018. Riau menempati posisi ke 15 dari seluruh provinsi di Indonesia. Prevalensi DM di Riau mengalami peningkatan dari angka 1,3\% tahun 2013 menjadi 1,9\% setelah 5 terakhir. Angka prevalensi yang terus meningkat di masa mendatang, khususnya angka kejadian di Provinsi Riau, menunjukkan bahwa diabetes mellitus adalah penyakit yang memerlukan perhatian dan penanganan serius (Imelda, 2019).

Perilaku kepatuhan terhadap empat pilar pengobatan merupakan inti dalam manajemen penyakit diabetes mellitus tipe 2. Penyakit diabetes mellitus tipe 2 adalah penyakit kronis sehingga membutuhkan perhatian dalam pengelolaan penyakit, dan menuntut individu yang sakit mampu melakukan manajemen pengobatan yang baik agar dapat tercapai kadar gula darah normal (euglycemia). Empat pilar pengelolaan penyakit diabetes melitus tipe 2 yang dimaksud seperti mengerti tentang penyakit diabetes secara baik, menjaga asupan makanan atau diet sesuai kebutuhan, berolahraga yang benar, memeriksa kadar gula darah, serta melakukan pengobatan diabetes mellitus tipe 2 secara rutin, termasuk perilaku pencegahan komplikasi yang mencakup perawatan diri, perilaku pemeriksaan mata, perilaku merokok (Suciana and Arifianto, 2019).

Pengelolaan pengobatan penyakit diabetes mellitus tipe 2 sangat penting dikarenakan penyakit ini bersifat kronis dan tidak sampai mencapai tingkat kesembuhan permanen. Karakteristik diabetes mellitus berupa gangguan metabolisme sebagai akibat dari efek resistensi insulin atau jumlah insulin dalam tubuh yang tidak mencukupi. (Idris, Hasyim and Utama, 2017) Tanda utamanya adalah kadar gula darah di atas batas normal. Jika kadar gula dalam darah berlebih, maka akan terjadi hiperglikemia, sedangkan jika kadar glukosa darah menurun dibawah normal akibat berlebihnya kadar insulin, akan menyebabkan hipoglikemia. Dengan demikian, apabila individu mengalami penyakit diabetes melitus memerlukan adanya manajemen diri yang kompleks agar mampu mencapai kadar gula darah dalam batas normal dan terhindar dari berbagai potensi komplikasi diabetes melitus (Carrizzo et al., 2018).

Pengendalian DM akan lebih efektif terutama pada usaha pencegahan dini melalui upaya perawatan mandiri pasien di keluarga.(Rahayu, Kamaluddin and Sumarwati, 2014) Pencegahan ditujukan terhadap timbulnya DM pada seseorang yang mempunyai faktor risiko dan pencegahan terjadinya komplikasi bagi penderita yang sudah mengidap DM. Tindakan pencegahan dini dapat ditempuh melalui program self-management yang akan mendorong penderita DM mengoptimalkan sumber daya yang dimiliki untuk mengelola penyakit yang dialaminya terutama pada pasien dengan penyakit kronis (Powers et al., 2016). Diabetes Self-Management Education (DSME) merupakan proses pendidikan kesehatan bagi individu atau keluarga dalam mengelola penyakit diabetes (Funnell et al., 2010). DSME menggunakan metode pedoman, konseling, dan intervensi perilaku untuk meningkatkan pengetahuan mengenai diabetes dan meningkatkan keterampilan individu dan keluarga dalam mengelola penyakit DM.

Fakultas Kedokteran Universitas Riau telah bekerjasama dengan pihak Desa Buluh Cina dalam membentuk Kampung Pelita Medika II dalam upaya mewujudkan peran pengabdian sivitas akademika kepada masyarakat, Pemilihan desa ini sesuai dengan visi FK UR yang memberi penekanan kepada peningkatan kesehatan bagi masyarakat yang tinggal di wilayah pesisir sungai.(Lesmana, Susanty and Afandi, 2019) Sejak tahun 2017, berbagai kegiatan yang dilakukan mahasiswa ataupun dosen telah dilakukan di Kampung Pelita ini, dan salah satunya kami telah mengidentifikasi tentang potensi peningkatan kasus penyakit Diabetes Melitus. Oleh karena itu kegiatan yang dilakukan ini bertujuan untuk memberikan edukasi tentang pencegahan Diabetes Melitus bagi kader dan masyarakat yang tinggal di desa Buluh Cina.

\section{METODE PENERAPAN}

Kegiatan edukasi umumnya dilakukan melalui ceramah dengan menggunakan media presentasi (Sampurna, 2020). Bentuk kegiatan yang kami lakukan adalah penyuluhan kepada masyarakat yang tinggal desa Buluh Cina di pinggiran sungai Kampar. Kegiatan ini dilakukan dengan melaksanakan program pendidikan dan promosi kesehatan secara berkelanjutan bersama mahasiswa Kukerta Abdimas.Dalam melakukan kegiatan ini, kami melakukan pendekatan dengan Puskesmas Siak Hulu II dan Kepala Desa Buluh Cina. Setelah ini melakukan koordinasi untuk menentukan jadwal pelaksanaan penyuluhan kepada para kader serta masyarakat.

Metode dalam pelaksanaan PKM ini dilakukan dalam 4 (empat) tahapan, yaitu (1) Sosialisasi, (2) Peningkatan kompetensi, (3) Pelaksanaan kegiatan, serta (4) Monitoring dan Evaluasi. Penggunaan 4 metode ini efektif digunakan untuk memberikan peningkatan pengetahuan dan keterampilan kader kesehatan dalam kesiapannya melakukan pendampingan kepada keluarga pasien DM. Kegiatan pendampingan yang dilakukan 
oleh TIM pengabdian ini menjadi cara yang digunakan untuk memberdayakan kader kesehatan sehingga tujuan dari pengabdian masyarakat tercapai.

Pelaksanaan kegiatan ini dilaksanakan di Desa Buluh Cina dari bulan Juli hingga Agustus 2020. Keberlangsungan secara mandiri oleh penderita DM dan kader pendamping dilakukan selama mahasiswa bertugas di desa binaan tersebut. Metode sosialisasi dilaksanakan untuk memberikan pemahaman mengenai program Pengabdian Kepada Masyarakat (PKM) (Maryanti and Lestari, 2020) dan alur serta tahapan program PKM. Sosialisasi dilakukan oleh dosen pendamping lapangan kepada:

a. Mahasiswa

1. Mahasiswa diberikan sosialisasi program Kelompok Pendamping Diabetes Self Management Education (KP-DSME) pada keluarga penderita DM.

2. Mahasiswa telah mendapatkan pembelajaran keterampilan klinik penanganan DM dengan "Empat Pilar Penatalaksanaan DM" di blok.

3. Mahasiswa diharapkan melakukan kontak dengan keluarga binaan masing-masing yang menjadi kader kesehatan dan keluarga yang mempunyai penyakit DM. Data yang didapat akan dikumpulkan dan dijadikan sasaran utama pengabdian. Setiap data baik penderita DM dan kader kesehatan diisi sesuai form yang disediakan oleh dosen pembimbing lapangan (form terlampir).

4. Pembimbing lapangan memberikan materi teknik pelatihan kader kesehatan kepada setiap mahasiswa. Materi pelatihan berupa pengelolan mandiri penderita DM menggunakan "empat pilar tatalaksana DM" (form terlampir) dan dikhususkan terhadap penderita DM dikeluarga binaannya masing-masing9.

b. Kader kesehatan

Data kader kesehatan diperoleh dari mahasiswa yang kontak langsung dengan keluarga binaan. Setiap kader kesehatan kita rekrut menjadi kader Pendamping Diabetes Self-Management Education (KP-DSME) pada keluarga penderita DM dan akan kita informasikan melalui sambungan telepon oleh mahasiswa yang menjadi keluarga binaan. Setiap kader yang di rekrut akan dilatih oleh oleh dokter pembimbing lapangan dan dimonitor oleh mahasiswa desa binaan dan dosen lapangan ketika jadwal kunjungan lapangan. Materi pelatihan berupa cara pendampingan pengelolaan DM dengan "empat pilar tatalaksana DM secara mandiri".

c. Penderita DM

Penderita DM yang ada di desa binaan akan diberikan sosialisasi tentang akan adanya pendampingan dalam mengobati penyakit DM yang diidapnya. Sosialisasi ini dilakukan di setiap keluarga binaan oleh mahasiswa dan dosen lapangan. Materi sosialisasi kepada penderita DM berupa empat pilar tatalaksana DM yang sesuai dengan kondisi penderita DM. selain itu pasien akan diberitahu akan ada kader kesehatan yang ikut melakukan pendampingan dalam pengelolaan DM secara mandiri.

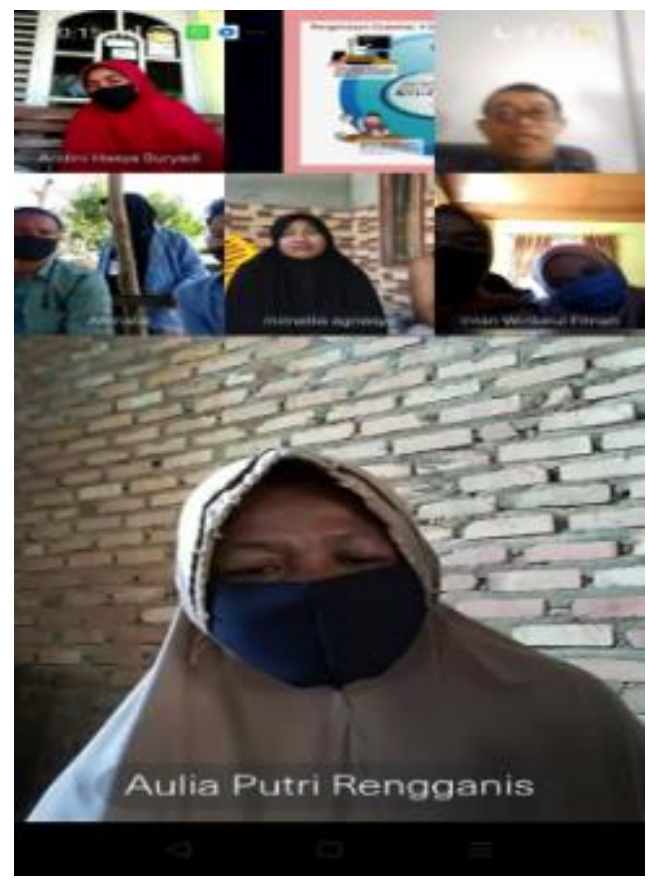

Gambar 1. Mahasiswa Kukerta bersama masyarakat menggunakan zoom meeting. 


\section{HASIL DAN KETERCAPAIAN SASARAN}

Masyarakat desa Buluh Cina merupakan masyarakat yang telah menjadi binaan FK UNRI. Sejak tahun 2017, desa ini telah menjadi Kampung Pelita Medika II, dimana mahasiswa kedokteran memiliki peran untuk melakukan kegiatan pengabdian. Masyarakat desa hidup dengan aman dan damai, jauh dari hiruk pikuk. Desa Bulu Cina terletak $15 \mathrm{Km}$ dari pusat kota sehingga masyarakatnya banyak yang berprofesi sebagai petani dan pengembala. Keadaan ekonomi di desa Buluh Cina terkategori rendah. Hal ini yang menyebabkan tingkat pendidikan di desa rendah, kebanyakan hanya sampai SMA.

Kegiatan pengabdian pengabdian dilakukan bersama mahasiswa Kukerta selama bulan Juli sampai dengan Agustus di kantor desa Buluh Cina dan juga di beberapa rumah kader DM. Peserta yang hadir berjumlah 20 orang. Adapun jalannya kegiatan pengabdian kepada masyarakat adalah sebagai berikut:

1. Penyuluhan tentang Posbindu

Kegiatan pertama adalah memberikan penyuluhan tentang posbindu. materi penyuluhan disampaikan oleh ketua pengabdian. Tujuan diberikan materi ini adalah untuk meningkatkan minat dan partisipasi masyarakat dalam kegiatan Posbindu dalam mendeteksi dini DM (Sengkey, Palandeng and Monintja, 2017).

2. Penyuluhan tentang diabetes

Untuk mengoptimalkan materi edukasi yang diberikan, maka tim pengabdian memberikan penyuluhan. Materi diberikan secara runut dimulai dari pengenalan beberapa penyakit terkait Diabetes dan upaya pencegahannya. Masyarakat sangat antusias mendengarkan penjelasan dari tim pengabdian. Kegiatan pengabdian ini juga dibantu oleh mahasiswa kukerta. Sebagai evaluasi kegiatan, beberapa peserta diberikan pertanyaan dan diminta untuk menjawab pertanyaan. Hasilnya peserta dapat menjawab dan memahami materi yang diberikan

3. Pemeriksaan gula darah

Kegiatan selanjutnya adalah pemeriksaan kadar gula darah. Kegiatan ini dilakukan untuk sebagai reward bagi masyarakat yang datang ke tempat acara pengabdian.

4. Media peraga untuk kader Posbindu

Pada akhir acara, tim pengabdian FK UNRI menyerahkan peraga untuk Posbindu berupa poster, alat gula darah dan plang edukasi DM. Diharapkan dengan adanya media peraga ini dapat mempermudah kader dalam melakukan edukasi tentang DM kepada masyarakat saat kegiatan Posbindu. Media peraga diterima oleh Kepala Desa dan Kader Posbindu.

Masyarakat sangat antusias mendengarkan penjelasan dari tim pengabdian. Melalui kegiatan ini diharapkan tidak hanya dapat dicegah penularan penyakit DM dalam peningkatan kualitas hidup masyarakat. (Suciana and Arifianto, 2019; Suyanto, Geater and Chongsuvivatwong, 2019). Sebagai evaluasi kegiatan, beberapa peserta diberikan pertanyaan dan diminta untuk menjawab pertanyaan. Hasilnya peserta dapat menjawab dan memahami materi yang diberikan.

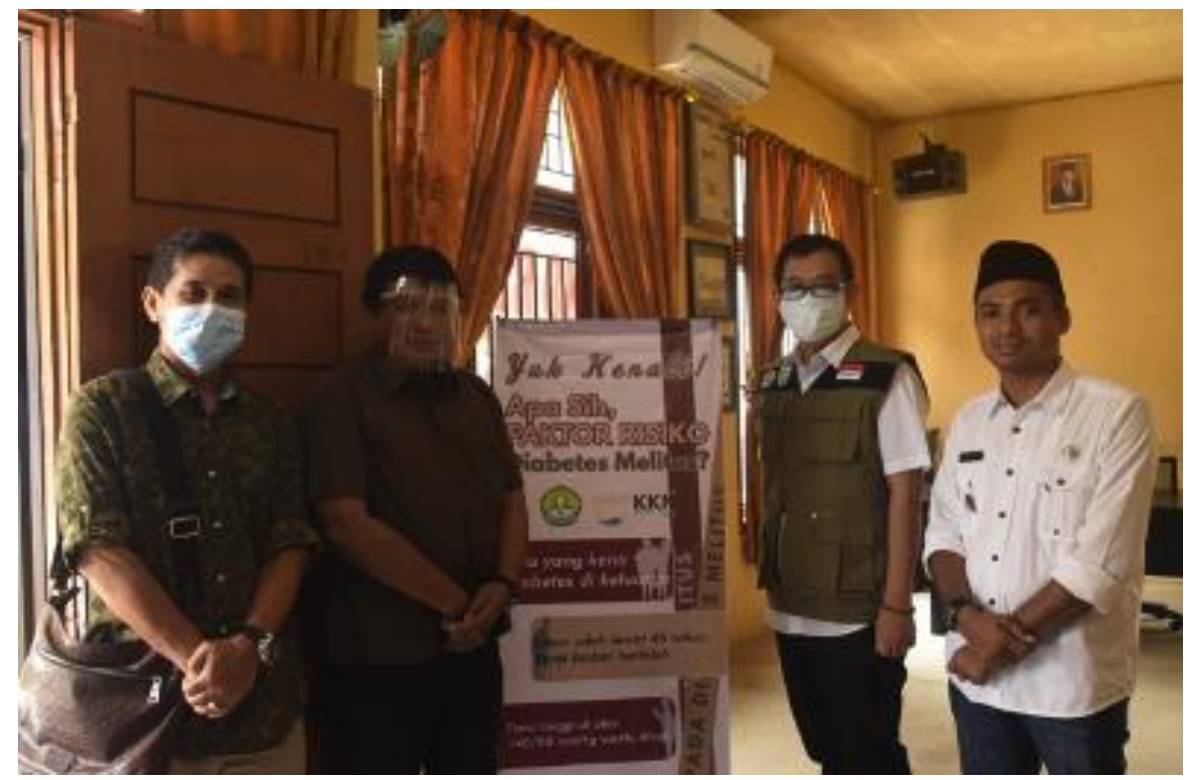

Gambar 2. Penyerahan Media Peraga DM di Kantor Kepala Desa BuluhCina oleh Tim Pengabdian 


\section{KESIMPULAN}

Kegiatan pengabdian kepada masyarakat berupa edukasi pencegahan DM dilakukan pada bulan Juli sampai dengan Agustus 2020 telah terlaksana dengan baik. Peserta yang hadir berjumlah 20 orang. Kegiatan dibagi menjadi 4 sesi yaitu: 1. Penyuluhan tentang Posbindu, 2. Penyuluhan Tentang Diabetes Melitus 3. Pemeriksaan Gula darah sewaktu 4. Penyerahan Media Peraga untuk Kader Posbindu. Kegiatan ini dihadiri oleh Kader Posbindu serta masyarakat yang berjumlah 20 orang. Partisipasi masyarakat aktif dapat dilihat dari respon masyarakat pada sesi tanya jawab. Diharapkan dengan adanya kegiatan pengabdian kepada masyarakat dapat meningkatkan derajat kesehatan masyarakat.

\section{UCAPAN TERIMA KASIH}

Terimakasih diucapkan kepada pihak Puskesmas Siak Hulu II dan Kepala Desa Buluh Cina yang telah memfasilitasi terlaksananya kegiatan ini.

\section{DAFTAR PUSTAKA}

Carrizzo, A., Izzo, C., Oliveti, M., Alfano, A., Virtuoso, N., Capunzo, M., Di Pietro, P., Calabrese, M., De Simone, E., Sciarretta, S., Frati, G., Migliarino, S., Damato, A., Ambrosio, M., De Caro, F. and Vecchione, C. 2018. The Main Determinants of Diabetes Mellitus Vascular Complications: Endothelial Dysfunction and Platelet Hyperaggregation. International Journal of Molecular Sciences, 19(10), 2968.

Funnell, M.M., Brown, T.L., Childs, B.P., Haas, L.B., Hosey, G.M., Jensen, B., Maryniuk, M., Peyrot, M., Piette, J.D., Reader, D., Siminerio, L.M., Weinger, K. and Weiss, M.A. 2010. National Standards for Diabetes SelfManagement Education. Diabetes Care, 33(Supplement_1), S89-S96.

Idris, H., Hasyim, H. and Utama, F. 2017. Analysis of Diabetes Mellitus Determinants in Indonesia: A Study from the Indonesian Basic Health Research 2013. Acta Med Indones, 49(4), 8.

Imelda, S. I. 2019. Faktor-Faktor Yang Mempengaruhi Terjadinya diabetes Melitus di Puskesmas Harapan Raya Tahun 2018. Scientia Journal, 8(1), 28-39.

Lesmana, S.D., Susanty, E. and Afandi, D. 2019. Gerakan Satu Rumah Satu Jumantik di Kampung Pelita Medika II Buluh Cina Kabupaten Kampar. ETHOS (Jurnal Penelitian dan Pengabdian), 7(2), 170-177.

Maryanti, E. and Lestari, E., 2020. Pendidikan kesehatan dalam rangka menuju panti asuhan bebas pedikulosis kapitis di Kecamatan Siak Hulu Kabupaten Kampar. Riau Journal of Empowerment, 3(2), 97-103. https://doi.org/10.31258/raje.3.2.97-103

Powers, M.A., Bardsley, J., Cypress, M., Duker, P., Funnell, M.M., Fischl, A.H., Maryniuk, M.D., Siminerio, L. and Vivian, E. 2016. Diabetes Self-management Education and Support in Type 2 Diabetes: A Joint Position Statement of the American Diabetes Association, the American Association of Diabetes Educators, and the Academy of Nutrition and Dietetics. 34(2), 11.

Rahayu, E., Kamaluddin, R. and Sumarwati, M. 2014. Pengaruh Program Diabetes Self-Management Education Berbasis Keluarga Terhadap Kualitas Hidup Penderita Diabetes Melitus Tipe II Di Wilayah Puskesmas II Baturaden. Jurnal Keperawatan Soedirman, 9, 10.

Sampurna, R. H. 2020. Meningkatkan kualitas hidup sehat masyarakat Dayak melalui lokakarya Sekolah Sehat di Kabupaten Landak Kalimantan Barat. Riau Journal of Empowerment, 3(2), 117-126. https://doi.org/10.31258/raje.3.2.117-126

Sengkey, Y., Palandeng, H.M.F. and Monintja, T.C.N. 2017. Pengetahuan Kader Posbindu terhadap Penyakit Diabetes Melitus. e-CliniC, [online] 5(1). Available at:

<https://ejournal.unsrat.ac.id/index.php/eclinic/article/view/15904> [Accessed 10 Oct. 2020].

Suciana, F. and Arifianto, D. 2019. Penatalaksanaan 5 Pilar Pengendalian DM Terhadap Kualitas Hidup Pasien DM Tipe 2. 9(4), 8 .

Suyanto, S., Geater, A. and Chongsuvivatwong, V. 2019. The Effect of Treatment during A Haze/Post-Haze Year on Subsequent Respiratory Morbidity Status among Successful Treatment Tuberculosis Cases. International Journal of Environmental Research and Public Health, 16(23), 4669. 